\title{
MANAGEMENT SCIENCE AND ITS RELATIONSHIP WITH THE SCIENCE OF PHYSICAL EDUCATION AND SPORT
}

\author{
Nichifor Florin ${ }^{1 *}$ \\ Onose lonuţ ${ }^{2}$ \\ 1,2 “Al. I. Cuza” University of Iasi, 3, Toma Cozma Street, Iasi, Romania
}

Keywords: organizational culture, organizational area, sport organization.

\begin{abstract}
This paper addresses to those who wish to understand managerial activity and what organizational culture represents in the Romanian context, both related to the field of sport and sports organizations. Its objective is to endow the people interested with theoretical and applicative information within a well-known field - management about a "pillar" that has been intensely and thoroughly studied in Romania mostly after the 90s: organizational culture. The interest for their own organization (i.e. an education establishment - school/theoretical high school/vocational high-school, faculty, university, sports club, sports association, firm, etc) shown by the manager and by his collaborators to obtain results/ performances is not a recent one. In exchange, the competition on the market of obtaining and training valuable human resources (pupils/ university students/ athletes/ teachers/ coaches) shifts the attention of sports topmanagers toward a managerial activity, which aims to be effective in the field of sport or education.
\end{abstract}

\section{Introduction}

Though relatively young, management science has become a coherent system, with a specific research objective and with its own scientific methodical methods and procedures, with specific terminology, thus proving a strongly interdisciplinary character (with elements from sociology, economy, psychology, anthropology, etc).

Several authors (Rusu, 1999, p.11) posit that management science represents an organized and coherent cluster of notions, principles, methods, and techniques meant to systematically explain and find solutions for management issues related to organization management and to their fields of activity, as well as to all organizational levels.

\footnotetext{
*E-mail: florinnichifor@yahoo.com, onoseionut@yahoo.com
} 


\section{Material and methods}

Managerial determinants in the field of physical education and sport:

a. Socioeconomic determinant:

- it refers to the dependence of management relations on the nature and existing modalities of property, on the nature of funding sources, on the level of local, regional, or national economic development.

b. Technical-material determinant:

- it is provided by the ways in which the characteristics of labour objectives and means influence the features of sports management and the relations within it, implicitly.

c. Human determinant:

- it is reflected by the interaction between two elements: the collective of each sports organization and the organizational managerial culture of the members of these structures.

In this context, it is essential not to neglect one of the main components of managerial activity: managerial relationship.

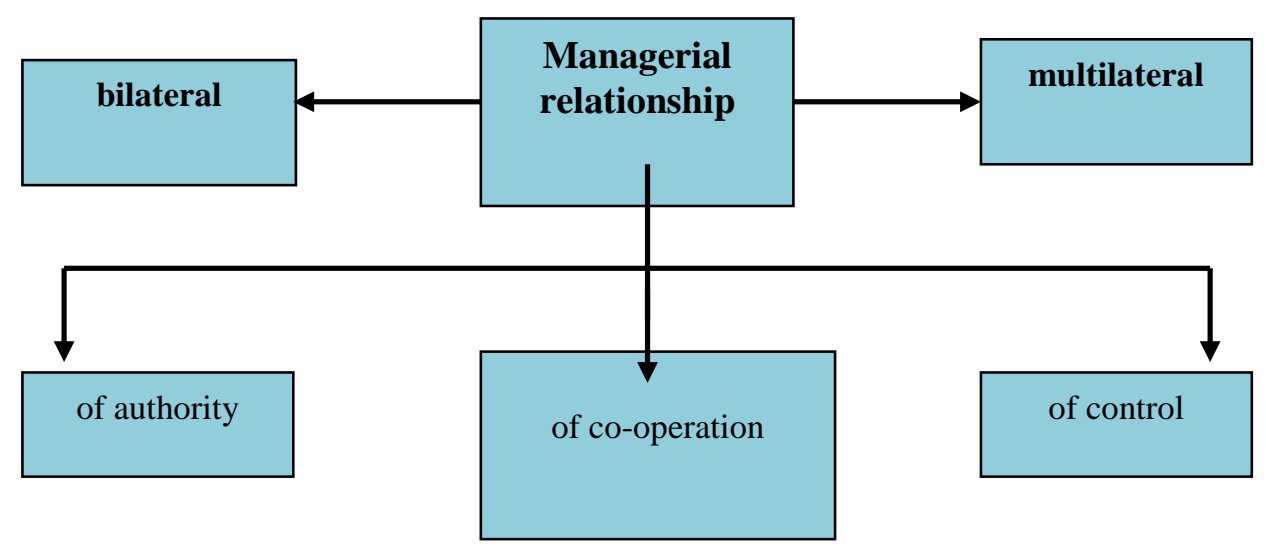

Figura 1. Typology of managerial relationships (processed after Mihăilescu N. 2006)

Managerial activity in the sports field includes the establishment of specific variables (Mihăilescu, 2006, p. 26):

- nature of legal person (public/private) and legal-normative framework;

- sports structure category (mono/multi-sport, of initiation, performance, great performance), and the dimension and complexity of sports activity (number of sections, number of employees, etc);

- human potential (coaches, athletes, managers, etc), training level, improvement possibilities; 
- the view of managers, of the personnel, of promoted management styles.

Types of resources in the management of physical education and sport:

Human resources represent the most important resource of sports activity From the perspective of activity contents, human resources are divided into two categories:

- managerial resources;

- execution resources.

They refer to coaches, physical education teachers, athletes, managers, officials, researchers, and to support, serving, and maintenance personnel, etc.

The categories of human resources necessary to a sports activity are determined by its specifics. Human resources necessary for organizing competitions can be divided into the following categories (Mihăilescu, 2006, p. 58): athletes and technicians, officials and organization personnel, serving personnel (sports base developer, meal, lodging, transportation), and managerial personnel (general manager, expert manager).

The capacity/ ability of managing correctly the human resources who are in contact with the manager are among the main attributes for the success of a managerial activity and in the sports field. Some of the managers neglect this aspect, which may entail negative and long-term consequences in their managerial activity (Bardel, Fontayne, Colombel, \& Schiphof, 2014, p. 171176).

Material resources comprise specific means, as follows: sports bases, fields, instalments, materials, equipments, etc. These material resources are different by sports branch and by activity at the same time.

Such an example is provided by athletics:

- material specific to the track and field: fences, hurdles, water jump hurdles, track starting blocks, batons;

- materials specific to long jumps - triple jump: landing pit, threshold, pit leveler, rulers, etc;

- means specific to long and high jumps: landing sector, crossbars, measuring devices;

- materials specific to throwing: sectors, stops, rulers, protection cages, throwing objects with specific shapes and different weights;

- materials necessary for officials: stop watches, stop watch devices, flags, starter pistols, rulers, and other measuring devices;

- materials necessary for secretariat activity: computer, copy machine, tables, chairs;

- locker rooms for athletes, officials, and other categories of personnel;

- athletes footwear is specific to events and different between similar events: example - difference between track spikes for sprint and hurdles, or between long and triple jump. 
These particular aspects concerning material resources were presented in order to highlight the complexity of managerial activities to conduct in order to observe all the regulations in the pre-season and mostly in the competition period (Nica \& Iftimescu, 2006, p. 12).

Financial resources refer to the funds necessary for organizing and conducting sports activities. From the perspective of managerial approach, we believe it necessary to underscore two aspects.

The first and most important of them refers to actions taken to ensure the financial funds necessary for organizing and conducting sports activity; the second aspect refers to the need of using funds effectively, which involves using the amounts responsibly and, in some cases, respecting expenditure levels and limits set by legislative acts (Mihăilescu, 2006).

Informational resources represent the category of resources with highest dynamic, which has gained increased importance. It is well known that information is essential to make a decision (seen as the main instrument of management) and that whoever holds information holds power (Prodan, 2005, p. 9-10).

Certain specialists include time as the fifth resource, "the most important management resource", because it conditions the most the quantity and quality of decisions adopted and of actions initiated to adopt them (Todea, 2003, p. 240). Time is a limited good, because it cannot be bought or sold, it cannot be stored or conserved; it is impossible to increase time, and its passage is both irrecoverable and irremediable (Mihăilescu, 2006).

\section{Results and Discussions}

Administration - which ensures the unitary organization of activities, which coordinates and directs them in agreement with organization goal - has become well known in all fields and at all levels as management. From an etymologic perspective, management comes from the Latin manus (manoeuvring, piloting). This word led to the Italian mannegio and to the French manège, borrowed into English as the verb "to manage" (to run, to lead).

Concerning the modern approaches to managerial theories, they focus on strategic aspects related to the development of strategic missions and to the promotion of values, to managerial change, to quality management promotion, to the optimization of relations and power of decision.

Numerous authors agree with the definition provided by H. Fayol, according to which "to manage is to forecast and plan, to organize, to command, to coordinate and to control” (cited by Mihăilescu, 2006, p.112). From another perspective, management involves planning, decision-making, leading the activity of a group of persons that act together to attain a common goal (Ray, 1997 cited by Todd, Andrew \& Sowieta, 2012, p. 49-56). 


\section{Conclusions}

If we were to synthesize the essence of various viewpoints expressed by specialists, we would posit that the management of sports activity could be defined by "the totality of specific processes and relations through which the resources of sports structures are organized, run, and managed both overall and on levels and competences, in order to attain goals effectively.” (Zakus, 2014, p. 133-158);

Considering the aforementioned definitions provided for management, we outline three main ideas below:

- Managers accomplish forecasting, organizing, coordinating, training, and controlling-assessing functions;

- Management is applied to all types of organizations, regardless of the field (economic, social, political, cultural, sports) or organization form (governmental/nongovernmental, patrimonial / non-patrimonial, public / private);

- Management is applied to all organization levels, from top to operational management;

- The purpose of management is to determine increased organizational efficacy and efficiency.

\section{References}

1. MIHĂILESCU, N. (2006). Management, marketing, legislaţie în activitatea sportivă, Piteşti: Universităţii, 26;

2. NICA P., IFTIMESCU, A. (2006). Management - suport de curs, Iaşi: Universităţii “Al. I. Cuza”, 12;

3. PRODAN, A. (2005). Managementul resurselor umane, Iaşi: Universităţii “Al. I. Cuza”, 9-10;

4. RUSU, C. (1999). Management strategic, București: All Back, 11;

5. TODEA, S.F. (2003). Managementul educaţiei fizice şi sportului, Bucureşti: Fundaţia România de Mâine, 240;

6. TODD S.Y., ANDREW D., SOWIETA S.E. (2009). A Personnel Management Case Study in a Canadian National Sport Organisation, Sport Management Review, 12, 49-56;

7. ZAKUS D.H. (2007). Critical and Ethical Thinking in Sport Management, Sport Management Review, 10, 133-158, 2007. 


\title{
ŞTIINTTA MANAGEMENTULUI ŞI RELAȚIA ACESTEIA CU ŞTIINTTA DOMENIULUI EDUCAŢIEI FIZICE ŞI SPORTULUI
}

\author{
Nichifor Florin ${ }^{1}$ \\ Onose lonut ${ }^{2}$ \\ ¿Universitatea "Al. I. Cuza”, Str. Toma Cozma, Nr. 3, Iași, Romania,
}

Cuvinte cheie: cultură organizatională, areal organizațional, organizație sportivă.

\section{Rezumat}

Lucrarea se adresează persoanelor, care doresc să înţeleagă activitatea managerială cât şi cea ce reprezintă cultura organizaţională, în contextul românesc, ambele raportate domeniului sportiv/organizaţiilor sportive. Obiectivul acesteia, este de a-i înzestra pe cei interesati cu un bagaj informaţional, teoretic şi aplicativ, dintr-un domeniu cunoscut - management - despre un „pilon”, studiat mai intens şi real în România, după deceniul '90 şi anume, cultură organizaţională. Interesul pentru propria organizaţie (fie aceasta instituţie de învăţământ-şcoală/liceu de profil teoretic/vocaţional, facultate, universitate, club sportiv, asociaţie sportivă, firmă, etc.), arătat de manager dar şi de colaboratorii săi, pentru obţinerea de rezultate/performanţe, nu este de dată recentă. În schimb, concurenţa pe piaţa obţinerii şi formării resurselor umane de valoare (elevi/studenţi/sportivi/profesori/antrenori) dirijeză atenţia top-managerului sportiv sau managerilor spre o activitate managerială, care încearcă să devină în domeniul sportului sau în sectorul de învăţământ, performantă.

\section{Introducere}

Relativ tânără, ştiinţa managementului s-a constituit într-un sistem închegat, cu un obiectiv propriu de cercetare, metode şi procedee metodice ştiinţifice de studiu, terminologie proprie, manifestându-se ca o ştiinţă cu un puternic caracter interdisciplinar, intersectându-se cu sociologia, economia, psiohologia, antropologia, etc.

O serie de autori (Rusu, 1999, p.11), consideră că ştiinţa managementului reprezintă un ansamblu organizat şi coerent de cunoştiinţe concepte, principii, metode şi tehnici) prin care se explică şi se soluţionează în mod sistematic, problemele de conducere, care vizează conducerea organizaţiilor şi a ariilor de activitate a acestora, precum şi toate nivelurile organizatorice.

\section{Material și metode}

Determinante manageriale în domeniul educației fizice și sportului:

a. Determinanta social-economică:

- se referă la dependenţa relaţiilor de management de natura şi modalităţile de existenţă a proprietăţii, de natura surselor de finanţare, de nivelul de dezvoltare economică local, regional sau naţional. 
b. Determinanta tehnico-materială:

- aceasta este dată de modalităţile în care caracteristicile obiectivelor şi mijloacelor muncii, influenţează trăsăturile managementului sportiv şi, implicit relaţiile din cadrul acestuia.

c. Determinarea umană:

- este reflectată de interacţiunea a două elemente: componenta colectivităţii fiecărei organizaţii sportive şi cultura managerială organizaţională a membrilor acestei structuri.În acest context, nu trebuie neglijată una dintre componentele principale ale activităţii manageriale şi anume relaţia managerială.

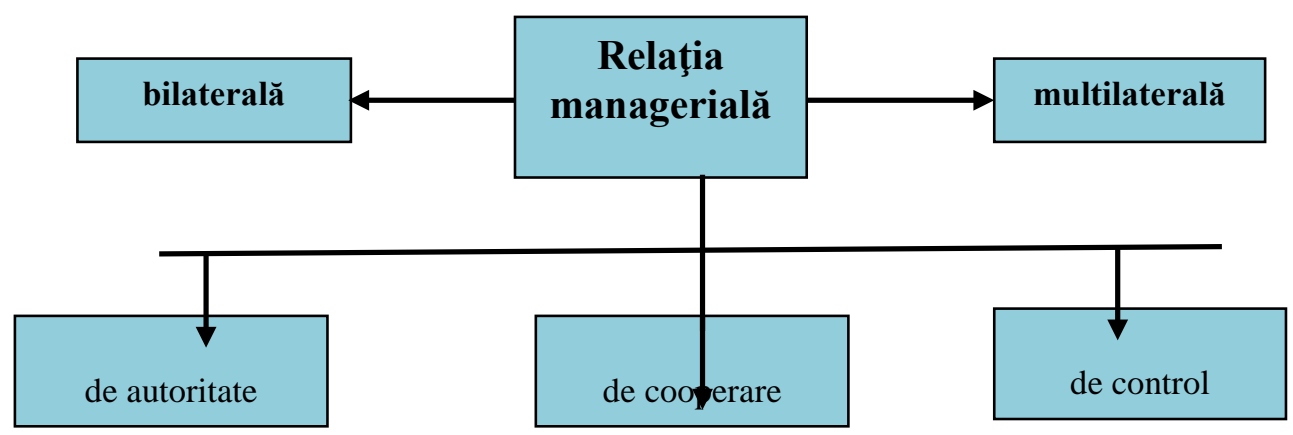

Figura 1. Tipologia relaţiilor manageriale (prelucrat după Mihăilescu N. 2006)

Activitatea managerială în domeniul sportului presupune stabilirea unor variabile specifice şi anume (Mihăilescu, 2006, p. 26):

- natura personalităţii juridice (public/privat) şi cadrul juridico-normativ;

- categoria de structură sportivă (mono/polisportivă, de iniţiere, performanţă, mare performanţă), precum şi de dimensiunea şi complexitatea activităţii sportive (număr de secţii, număr de salariaţi, etc.);

- potenţialul uman (antrenori, sportivi, manageri, etc.), nivelul de pregătire, posibilităţile de perfecţionare;

- concepţia managerilor, a personalului, stilurile de management promovate.

Tipuri de resurse în managementul educației fizice și sportului:

Resursele umane reprezintă cele mai importante resurse ale activităţii sportive (Lăzărescu, 1996; Lador, 2000). Din perspectiva conţinutului activităţii desfăşurate, resursele umane se împart în două categorii:

- resurse manageriale;

resurse de execuţie.

Acestea se referă la: antrenori, profesori de educaţie fizică, sportivi, manageri, arbitri, cercetători, personal de susţinere, de deservire şi întreţinere, etc. 
Categoriile de resurse umane necesare unei activităţi sportive sunt determinate de specificul acesteia.

Resursele umane necesare organizării de competiţii pot fi împărţite în următoarele categorii (Mihăilescu, 2006, p. 58): sportivi şi tehnicieni, arbitri şi personal de organizare, personal de deservire (amenajator baze sportive, masă, cazare, transport) şi personal managerial (manager general, manager pe domeniul de competenţă).

Capacitatea, abilitatea gestionării corecte a resurselor umane cu care interacţionează managerul, este unul din atributele principale ale succesului unei activităţi manageriale şi în domeniul sportului. Neglijarea acestui aspect, de unii dintre manageri, poate avea consecinţe negative şi de durată în activitatea managerială pe care o desfăşoară (Bardel, Fontayne, Colombel \& Schiphof, 2014, p. 171-176).

Resursele materiale sunt constituite din mijloace specifice constând din: baze sportive, terenuri, instalaţii, materiale, echipamente şi altele asemenea. Aceste resurse materiale sunt diferite în funcţie de ramura de sport concomitent cu activitatea desfăşurată.

Un exemplu în acest sens ar fi disciplina atletism:

- materiale specifice pistei de atletism: garduri, obstacole, groapă cu apă, blocstarturi, beţe de ştafetă;

- materiale specifice sectorului de lungime - triplusalt: groapă cu nisip, prag, niveletor groapă, rulete, etc.;

- mijloace specifice sectoarelor de săritura în lungime şi prăjină: sector de aterizare, stâlpi, ştachetă măsurători înălţime;

- materiale specifice probelor de aruncări: sectoare amenajate, opritori, rulete, cuşti de protecţie, obiecte de aruncat de forme specifice şi greutăţi diferite;

- materiale necesare desfăşurării activităţii de arbitraj: cronometre, instalaţii de cronometraj, fanioane, pistol start, rulete şi alte aparate de măsură;

- materiale necesare activităţii de secretariat: calculator, copiator, mese, scaune;

- vestiare pentru sportivi, arbitrii şi alte categorii de personal;

- încălţămintea sportivilor este specifică probelor şi diferenţiată între probe asemănătoare: exemplu - diferenţa pantofilor cu cuie între probele de sprint pe plat şi peste garduri, ori între lungime şi triplusalt.

Aceste aspecte particulare, în cea ce privesc resursele materiale, au fost prezentate cu scopul de a sublinia complexitatea acţiunilor manageriale ce trebuie realizate pentru buna desfăşurare a activităţii pe care o încadrăm în prevederile regulamentare în perioada premergătoare competiţiei şi în special în timpul desfăşurării acesteia (Nica \& Iftimescu, 2006, p.12).

Resursele financiare se referă la fondurile necesare organizării şi desfăşurării activităţilor sportive. Din perspectiva abordării manageriale considerăm necesară evidenţierea a două aspecte: primul aspect şi cel mai important se referă la acţiunile desfăşurate pentru asigurarea fondurilor financiare necesare organizării şi desfăşurării activităţii sportive, cel de-al doilea aspect se referă la necesitatea utilizării eficiente a fondurilor, cea ce presupune 
angajarea responsabilă a sumelor şi, în unele cazuri, respectarea unor naturi de cheltuieli şi baremuri stabilite ptin acte normative (Mihăilescu, 2006).

Resursele informaţionale reprezintă categoria de resurse cu cea mai mare dinamică, căreia i se acordă o importanţă din ce în ce mai mare. Este cunoscut faptul că informaţia stă la baza deciziei (considerat principalul instrument de management) şi recunoscut aspectul că cine deţine informaţia deţine puterea (Prodan, 2005, p. 9-10).

Timpul este consideră de unii specialişti ca fiind a cincea resursă, ,cea mai importantă resursă a managementului”, întrucât condiţionează în modul cel mai important cu putinţă cantitatea şi calitatea deciziilor adoptate şi acţiunile iniţiate pentru adoptarea lor (Todea, 2003, p. 240).

Timpul este un bun rar şi limitat, nu poate fi vândut sau cumpărat, nu poate fi stocat sau pus deoparte, este imposibil să mărim timpul, iar trecerea acestuia este irecuperabilă şi iremediabilă (Mihăilescu, 2006).

\section{Rezultate şi discuții}

Activitatea de conducere, cu rol de a asigura organizarea unitară a activităţilor, de a coordona şi dirija în concordanţă cu scopurile organizaţiilor este cunoscută astăzi în toate domeniile şi la toate nivelurile sub denumirea de management. Din punct de vedere etimologic cuvântul management își are originea în expresia latină „,manus” (manavrare, pilotare).

Derivat din acest termen s-au format cuvintele „mannegio” în limba italiană şi „manege” în limba franceză, de unde a fost împrumutat în limba engleză sub forma verbului „to manage” (a administra, a conduce).

În cea ce priveşte abordările moderne ale teoriilor manageriale, acestea pun accent pe aspecte strategice care vizează dezvoltarea misiunilor strategice şi promovarea valorilor, schimbarea managerială, promovarea managementului de calitate, optimizarea relaţiilor şi a puterii de decizie.

Numeroşi autori consideră de actualitate definiţia dată de H. Fayol, conform căreia ,,activitatea de management înseamnă a prevedea şi a plănui, a organiza, a comanda, a coordona şi a controla” (citat de Mihăilescu, 2006, p.112).

\section{Concluzii}

În esenţă şi sintetizând mai multe puncte de vedere exprimate de specialişti, putem considera că managementul activităţii sportive, poate fi definit ca ,totalitatea proceselor şi relaţiilor specifice prin intermediul cărora se organizează, se administrează şi se gestionează resursele unei structuri a sportului, atât pe ansamblu, cât şi pe niveluri şi componente, cu scopul realizării cu eficienţă a obiectivelor propuse” (Zakus, 2014, p. 133-158).

În contextul definiţiilor managementului prezentate mai sus considerăm că putem sintetiza următoarele idei principale:

- Managerii îndeplinesc funcţii de previziune, de organizare, coordonare, de antrenare şi de control-evaluare; 
Managementul se aplică la toate tipurile de organizaţii, indiferent de domeniul în care acesta funcţionează (economic, social, politic, cultural, sportiv) sau de forma de organizare (guvernamental/neguvernamental, patrimonial/nepatrimonial, public/privat);

- Managementul se aplică la toate nivelurile organizaţionale, de la cel de top la cel operaţional;

- Scopul managementului este determinarea creşterii eficacităţii şi eficienţei organizaţionale. 